\title{
The Potential Cost-Effectiveness of Pharmacist Delivered Brief Intervention for Alcohol Misuse
}

\author{
Héctor José Navarro ${ }^{1}$, Anthony Shakeshaft ${ }^{1^{*}}$, Christopher M Doran ${ }^{2}$ and Dennis J Petrie ${ }^{3}$ \\ ${ }^{1}$ National Drug and Alcohol Research Centre (NDARC), UNSW (University of NSW), Australia \\ ${ }^{2}$ Hunter Medical Research Institute and the University of Newcastle, Room 3016, HMRI Building, Kookaburra Circuit, New Lambton Heights, NSW, 2305, Australia \\ ${ }^{3}$ Centre for Health Policy, Programs \& Economics, Melbourne School of Population and Global Health, Level 4, 207 Bouverie Street, University of Melbourne, VIC, 3010, \\ Australia
}

"Corresponding author: Anthony Shakeshaft, National Drug and Alcohol Research Centre (NDARC), UNSW (University of NSW), Australia, Tel: 61-2-9385-0333; Email: a.shakeshaft@unsw.edu.au

Received date: Aug 14, 2014; Accepted date: Sept 22, 2014; Published date: Sept 29, 2014

Copyright: (C) 2014 Shakeshaft A, et al. This is an open-access article distributed under the terms of the Creative Commons Attribution License, which permits unrestricted use, distribution, and reproduction in any medium, provided the original author and source are credited.

\begin{abstract}
The provision of brief intervention ( $\mathrm{BI}$ ) for alcohol misuse in community pharmacies appears to be feasible, although little has been done in determining its impact. This research aims to model pharmacists' delivered screening, $\mathrm{Bl}$ and costs per additional risky drinker reducing alcohol consumption relative to current practice in rural Australia. A decision model was developed to assess costs and changes in outcomes from pharmacist-delivered screening and $\mathrm{BI}$ on alcohol consumption in 10 rural communities in New South Wales, Australia. Nine different scenarios were utilised to test the robustness of results to variations in key parameters. Based on evidence from current practice, approximately $22 \%$ of all risky drinkers in a defined community would reduce alcohol consumption annually, of which about $0.02 \%$ would do so because of pharmacist-delivered screening and $\mathrm{BI}$ and $1 \%$ would do so because of pharmacist screening only. Realistic increments of $10 \%$ and $20 \%$ in pharmacist-delivered screening and $\mathrm{BI}$ would reduce the proportion of risky drinkers by $0.5 \%$ and $1.6 \%$ at a cost of AUD $\$ 50$ and AUD $\$ 40$ respectively, per additional risky drinker reducing alcohol consumption. These findings suggest that increments in pharmacistdelivered screening and $\mathrm{BI}$ rates may result in potential cost-effective reductions in alcohol consumption, although its widespread adoption is unlikely to occur because almost all risky drinking pharmacy customers would need to be screened to achieve a reasonable effect size.
\end{abstract}

Keywords: Brief intervention; Alcohol misuse; Pharmacist; Risky drinker; Cost-effectiveness

\section{Introduction}

An estimated $80 \%$ of the Australian population report drinking alcohol, of whom $20 \%$ consume above the Australian recommended guidelines for risky drinking over their lifetime and 28\% report drinking more than four standard drinks on a single drinking occasion at least once a month [1,2]. Primary care has long been considered an ideal setting in which to deliver interventions to reduce these rates of risky drinking, on the basis that the vast majority of a population access primary care services [3,4]. In attempting to reduce the proportion of risky drinkers, Outcomes from meta-analyses of randomized controlled trials (RCTs) of brief intervention (BI) for alcohol misuse delivered in primary care, have generally shown mean difference reductions in alcohol consumption of 38 grams per week $(\mathrm{g} / \mathrm{wk})$ in the intervention groups compared to controls $[5,6]$. They have also been found to be cost-effective, relative to 'usual care' $[7,8]$ and other interventions $[9,10]$, for prevention of alcohol-related disease and injury.

As part of a World Health Organization (WHO) study, the current rate with which $\mathrm{BI}$ is provided in primary care settings was estimated to achieve a reduction in the proportion of hazardous drinkers in a population of between $4.9 \%$ and $6.4 \%$, after adjusting for treatment adherence and the target coverage of the population [10]. Although the effectiveness of BI may be less than optimal, the most likely explanation for this relatively modest impact is that universal, routine provision of BI by GPs has been difficult to achieve [4,11-13]. A recent study estimated that if all GPs provided a BI to all risky drinkers with whom they have a consultation in a 12-month period, approximately $36 \%$ of all risky drinkers in a population would reduce their alcohol consumption [14]. Even if this unlikely scenario could be achieved, that the effect is limited to $36 \%$ of risky drinkers most likely reflects that GPs do not routinely access sub-groups within communities that are at high-risk of excessive alcohol consumption and harm, especially young males [15-19].

Health professionals other than GPs can play an important role in delivering health promotion in primary care $[17,20,21]$. Community pharmacists are in an ideal position to deliver alcohol BI for a number of reasons. First, they can access vulnerable sub-populations who rarely discuss their health [22] or drinking behaviour with GPs [17], particularly young males. Second, they are regarded as a valuable source of information on health education and referral for a range of health matters [17,20,23-26]. Third, an accepted part of their medication dispensing role is to provide relevant information on alcohol and other drug interactions [17,20,27].

Although pharmacist delivered screening and BI for alcohol misuse appears feasible $[17,23,28,29]$ only two intervention outcome studies have been published [20,29]. Across both studies the average proportion of risky drinkers reducing any consumption was $34 \%$, but only one study reported the mean reduction in alcohol consumption after BI: 2.8 units per week, equivalent to $22.4 \mathrm{~g} / \mathrm{wk}$ [20]. Prior to replicating the GP research literature with multiple pharmacy-based intervention trials, the Alcohol Action in Rural Communities (AARC) 
Page 2 of 10

project provided a timely opportunity to model the likely realistic contribution of pharmacist-delivered screening and BI in reducing alcohol consumption across a defined population [30].

This study has two specific aims. First, to model current practice, in terms of the proportion of risky drinkers in a community that visit a community pharmacist during a year and subsequently reduce their drinking. Second, to identify the cost per additional risky drinker who reduces alcohol consumption as a consequence of being screened in a community pharmacy with and without receiving a $\mathrm{BI}$, relative to current practice.

\section{Methods}

\section{Modeling costs and reduction in alcohol consumption from BI}

A decision model (Figure 1) was developed to predict: the proportion of risky drinkers who visit a pharmacy annually; the proportion of risky drinkers who are screened; the proportion of risky drinkers who are screened and receive a $\mathrm{BI}$; and the proportion of risky drinkers who are screened, receive a $\mathrm{BI}$ and reduce alcohol consumption.

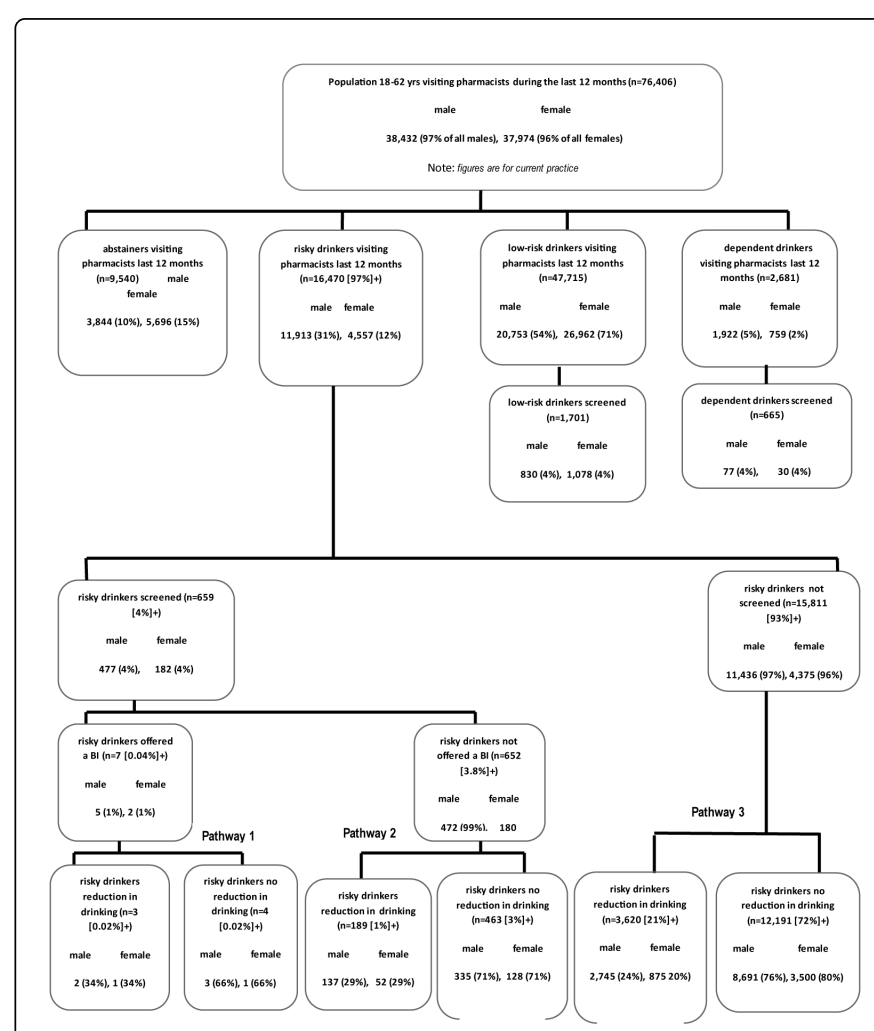

Figure 1: Decision model for presumptive risky drinkers receiving pharmacist-delivered screening and BI for alcohol misuse.

+of all risky drinkers in the community; total percentages may not sum due to rounding; $\mathrm{BI}=$ Brief intervention.

To analyze the effects of possible future events, nine different scenarios (Table 1) with increments of $10 \%, 20 \%$ and up to $100 \%$ either in screening (scenarios 1.1-1.3), or in BI (scenarios 2.1-2.3), or in the combination of screening and BI (scenarios 3.1-3.3), were compared to current practice. The increments of $10 \%$ and $20 \%$ were selected as outcomes that could realistically be achieved [13], while the increment to $100 \%$ was used as a 'best-case' scenario.

\section{Data sources}

Community data to populate the decision model were obtained from 1,540 surveys completed by randomly selected individuals $(40.3 \%$ survey response rate $[1,540 / 3,819])$ in the 10 AARC experimental communities in 2005. The survey asked questions about alcohol consumption, alcohol related harms, community actions to reduce alcohol problems, health status and demographics [30,31]. Only data from the 10 experimental communities were used because they were the communities in which pharmacists received screening and BI training and, consequently, for which costs were able to be estimated. The sample consisted of 18-62 year olds and, to optimize representativeness, was selected using the age and gender distribution of these communities according to the Australian Bureau of Statistics' (ABS) 2001 Census of Population and Housing [32]: age 18 coincides with the minimum age for voting and legal drinking in Australia and those over 62 contribute relatively little to alcohol-related harm $[31,33]$.

\section{Prevalence of risky drinkers}

Based on scores on the 10-item Alcohol Use Disorders Identification Test (AUDIT), which was embedded in the community survey, respondents were classified as abstainers (never drink), lowrisk drinkers (score $\leq 7$ ), risky drinkers (score 8-19, representing WHO categories of hazardous and harmful drinking), and alcohol dependent drinkers (score $\geq 20$ ) $[34,35]$. To estimate the number of people in each drinking category across the 10 communities, the proportions of survey respondents in each drinking category were multiplied by population data for the 10 AARC experimental communities, by age and gender, obtained from the $2006 \mathrm{ABS}$ census $(\mathrm{N}=79,177$ residents, 18 to 62 year olds, in the 10 AARC experimental communities) [32].

\section{Number of visits to a pharmacy and rates of screening and BI}

The proportion of risky drinkers (by gender and age) that visit a community pharmacy annually was estimated from the number of risky drinkers who did not answer (a) to the community survey question "In your community, how many times in the past 12 months have you received information on alcohol when making a purchase from a chemist?", to which possible answers were: (a) Have not been to chemist, (b) Never, and (c) Number of times (open ended response). The current rate with which BI was provided to risky drinkers by pharmacists was estimated from answers (b) and (c) to this same question.

In 2006, the AARC project liaised with, and provided 3,500 alcohol self-assessments (the AUDIT questionnaire) to, 44 pharmacists from all community pharmacies $(\mathrm{N}=35)$ in the 10 AARC experimental communities. Screening rates of alcohol misuse were estimated based on the number of alcohol consumption self-assessments that were completed by their customers in 2006 (the self-assessments had a unique numbering code so the number completed could be easily identified). 
Citation: Navarro HJ, Shakeshaft A, Doran CM, Petrie DJ (2014) The Potential Cost-Effectiveness of Pharmacist Delivered Brief Intervention for Alcohol Misuse. J Gen Practice 2: 173. doi:10.4172/2329-9126.1000173

Page 3 of 10

\begin{tabular}{|c|c|c|c|c|c|c|}
\hline & $\begin{array}{l}\text { Screening rate of low- } \\
\text { risk drinkers }\end{array}$ & $\begin{array}{l}\text { Screening rate of } \\
\text { dependent drinkers }\end{array}$ & $\begin{array}{l}\text { Screening rate of } \\
\text { risky drinkers }\end{array}$ & $\begin{array}{l}\text { BI rate of risky } \\
\text { drinkers }\end{array}$ & $\begin{array}{l}\text { Proportion of risky } \\
\text { drinkers reducing their } \\
\text { drinking from } \mathrm{BI} \\
\text { (pathway 1) }\end{array}$ & $\begin{array}{l}\text { Proportion of risky } \\
\text { drinkers reducing their } \\
\text { drinking from screening } \\
\text { (pathway 2) }\end{array}$ \\
\hline Current practice & $3 \% \mathrm{M}, 4 \% \mathrm{~F}$ & $3 \% \mathrm{M}, 4 \% \mathrm{~F}$ & $3 \% \mathrm{M}, 4 \% \mathrm{~F}$ & $1 \% \mathrm{M}, 1 \% \mathrm{~F}$ & $34 \% \mathrm{M}, 34 \% \mathrm{~F}$ & $29 \% \mathrm{M}, 29 \% \mathrm{~F}$ \\
\hline \multicolumn{7}{|l|}{ Nine scenarios } \\
\hline \multicolumn{7}{|l|}{ Screening scenarios } \\
\hline $\begin{array}{l}10 \% \text { increase in } \\
\text { screening }\end{array}$ & $\begin{array}{l}{ }^{*} 13 \% \mathrm{M} \\
{ }^{*} 14 \% \mathrm{~F}\end{array}$ & ${ }^{*} 13 \% \mathrm{M},{ }^{*} 14 \% \mathrm{~F}$ & ${ }^{*} 13 \% \mathrm{M},{ }^{*} 14 \% \mathrm{~F}$ & $1 \% \mathrm{M}, 1 \% \mathrm{~F}$ & $34 \% \mathrm{M}, 34 \% \mathrm{~F}$ & $29 \% \mathrm{M}, 29 \% \mathrm{~F}$ \\
\hline $\begin{array}{l}20 \% \text { increase in } \\
\text { screening }\end{array}$ & ${ }^{*} 23 \% \mathrm{M},{ }^{*} 24 \% \mathrm{~F}$ & ${ }^{*} 23 \% \mathrm{M},{ }^{*} 24 \% \mathrm{~F}$ & ${ }^{*} 23 \% \mathrm{M},{ }^{*} 24 \% \mathrm{~F}$ & $1 \% \mathrm{M}, 1 \% \mathrm{~F}$ & $34 \% \mathrm{M}, 34 \% \mathrm{~F}$ & $29 \% \mathrm{M}, 29 \% \mathrm{~F}$ \\
\hline $\begin{array}{l}\text { Increase in screening } \\
\text { up to } 100 \%\end{array}$ & ${ }^{*} 100 \% \mathrm{M},{ }^{*} 100 \% \mathrm{~F}$ & ${ }^{*} 100 \% \mathrm{M},{ }^{*} 100 \% \mathrm{~F}$ & ${ }^{*} 100 \% \mathrm{M},{ }^{*} 100 \% \mathrm{~F}$ & $1 \% \mathrm{M}, 1 \% \mathrm{~F}$ & $34 \% \mathrm{M}, 34 \% \mathrm{~F}$ & $29 \% \mathrm{M}, 29 \% \mathrm{~F}$ \\
\hline \multicolumn{7}{|l|}{ Bl scenarios } \\
\hline $10 \%$ increase in $\mathrm{BI}$ & $3 \% \mathrm{M}, 4 \% \mathrm{~F}$ & - & - & ${ }^{*} 11 \% \mathrm{M},{ }^{*} 11 \% \mathrm{~F}$ & $34 \% \mathrm{M}, 34 \% \mathrm{~F}$ & $29 \% \mathrm{M}, 29 \% \mathrm{~F}$ \\
\hline $20 \%$ increase in $\mathrm{BI}$ & $3 \% \mathrm{M}, 4 \% \mathrm{~F}$ & - & - & ${ }^{*} 21 \% \mathrm{M},{ }^{*} 21 \% \mathrm{~F}$ & $34 \% \mathrm{M}, 34 \% \mathrm{~F}$ & $29 \% \mathrm{M}, 29 \% \mathrm{~F}$ \\
\hline $\begin{array}{l}\text { Increase in } \mathrm{BI} \text { up to } \\
100 \%\end{array}$ & $3 \% \mathrm{M}, 4 \% \mathrm{~F}$ & - & - & $\begin{array}{l}{ }^{*} 100 \% \mathrm{M},{ }^{*} 100 \% \\
\mathrm{~F}\end{array}$ & $34 \% \mathrm{M}, 34 \% \mathrm{~F}$ & $29 \% \mathrm{M}, 29 \% \mathrm{~F}$ \\
\hline \multicolumn{7}{|l|}{$\begin{array}{l}\text { Screening and } \mathrm{BI} \\
\text { scenarios }\end{array}$} \\
\hline $\begin{array}{l}10 \% \quad \text { increase in } \\
\text { screening and } \mathrm{BI}\end{array}$ & ${ }^{*} 13 \% \mathrm{M},{ }^{*} 14 \% \mathrm{~F}$ & ${ }^{*} 13 \% \mathrm{M},{ }^{*} 14 \% \mathrm{~F}$ & ${ }^{*} 13 \% \mathrm{M},{ }^{*} 14 \% \mathrm{~F}$ & ${ }^{*} 11 \% \mathrm{M},{ }^{*} 11 \% \mathrm{~F}$ & $34 \% \mathrm{M}, 34 \% \mathrm{~F}$ & $29 \% \mathrm{M}, 29 \% \mathrm{~F}$ \\
\hline $\begin{array}{lr}20 \% \quad \text { increase in } \\
\text { screening and } \mathrm{BI}\end{array}$ & ${ }^{*} 23 \% \mathrm{M},{ }^{*} 24 \% \mathrm{~F}$ & ${ }^{*} 23 \% \mathrm{M},{ }^{*} 24 \% \mathrm{~F}$ & ${ }^{*} 23 \% \mathrm{M},{ }^{*} 24 \% \mathrm{~F}$ & ${ }^{*} 21 \% \mathrm{M},{ }^{*} 21 \% \mathrm{~F}$ & $34 \% \mathrm{M}, 34 \% \mathrm{~F}$ & $29 \% \mathrm{M}, 29 \% \mathrm{~F}$ \\
\hline $\begin{array}{l}\text { Increase in screening } \\
\text { and Bl up to } 100 \%\end{array}$ & ${ }^{*} 100 \% \mathrm{M},{ }^{*} 100 \% \mathrm{~F}$ & ${ }^{*} 100 \% \mathrm{M},{ }^{*} 100 \% \mathrm{~F}$ & ${ }^{*} 100 \% \mathrm{M},{ }^{*} 100 \% \mathrm{~F}$ & $\begin{array}{l}{ }^{*} 100 \% \mathrm{M},{ }^{*} 100 \% \\
\mathrm{~F}\end{array}$ & $34 \% \mathrm{M}, 34 \% \mathrm{~F}$ & $29 \% \mathrm{M}, 29 \% \mathrm{~F}$ \\
\hline
\end{tabular}

Table 1: Scenario options.

${ }^{*}$ Percentage increments; $\mathrm{BI}=$ Brief intervention .

\section{Proportion of presumptive risky drinkers reducing their alcohol consumption}

As shown in Figure 1, risky drinkers can reduce their drinking via 3 different pathways when visiting a community pharmacy. The first pathway involves risky drinkers who are screened, receive a BI and reduce their drinking. Based on the average results of the only two community pharmacy-based alcohol intervention outcome studies published to date, it is assumed for this analysis that $34 \%$ of risky drinkers who receive a BI in a community pharmacy reduce their consumption $[20,29]$. The second pathway is risky drinkers who are screened, but do not receive a BI and reduce their drinking. Since the two published pharmacy-based studies did not report the effect of screening alone, and, based on the assumptions that screening alone is less effective than screening and BI and more effective than no screening and no BI, it is assumed for this analysis that $29 \%$ (mid estimate from $34 \%$ in pathway one and $24 \%$ in pathway three) of risky drinkers in this group reduce their consumption. The third pathway involves risky drinkers who are not screened, do not receive a BI but reduce their drinking. For this group, the percentage of risky drinkers who reduce their drinking (24\% males; $20 \%$ females) is adopted from previously published estimates used in a similar primary care scenario analysis study [36].

\section{Sensitivity Analyses}

Based on the assumption that BI (pathway one) is more effective than screening (pathway two) and in order to maintain differences in effectiveness between them, two one-way sensitivity analyses were carried out to explore the robustness of results to variations in the effectiveness rates across current practice and the nine scenarios.

First, given an estimated $34 \%$ of risky drinkers who visit a pharmacist and are screened and receive a BI actually reduce their drinking (pathway one, Figure 1), and an estimated 29\% of risky drinkers who visit a pharmacist and are screened but do not receive a BI also reduce their drinking (pathway two, Figure 1), the sensitivity analysis increases only the effectiveness rate for pathway one by $10 \%$, from $34 \%$ to $44 \%$, across current practice and the nine scenarios (Table 2, column A). The difference between pathway one and pathway two equates to $15 \%$.

Second, the sensitivity analysis increases the effectiveness rate by $10 \%$, from $34 \%$ to $44 \%$, for pathway one (Table 2 , column B) and by $5 \%$, from $29 \%$ to $34 \%$, for pathway two (Table 2 , column C). The difference between pathway one and pathway two equates to $10 \%$. 
Citation: Navarro HJ, Shakeshaft A, Doran CM, Petrie DJ (2014) The Potential Cost-Effectiveness of Pharmacist Delivered Brief Intervention for Alcohol Misuse. J Gen Practice 2: 173. doi:10.4172/2329-9126.1000173

Page 4 of 10

\begin{tabular}{|c|c|c|c|}
\hline Sensitivity analyses & $A^{* *}$ & $\mathrm{~B}^{* * *}$ & $C^{* * * * *}$ \\
\hline & $\begin{array}{l}\text { Increasing effectiveness by } \\
10 \% \text { for Pathway } 1\end{array}$ & $\begin{array}{l}\text { Increasing effectiveness by } \\
10 \% \text { for Pathway } 1\end{array}$ & $\begin{array}{l}\text { Increasing effectiveness by } 5 \% \\
\text { for Pathway } 2\end{array}$ \\
\hline Current practice & ${ }^{*} 44 \% \mathrm{M},{ }^{*} 44 \% \mathrm{~F}$ & ${ }^{*} 44 \% \mathrm{M},{ }^{*} 44 \% \mathrm{~F}$ & ${ }^{*} 34 \% \mathrm{M},{ }^{*} 34 \% \mathrm{~F}$ \\
\hline \multicolumn{4}{|l|}{ Nine scenarios } \\
\hline \multicolumn{4}{|l|}{ Screening scenarios } \\
\hline $1.110 \%$ increase in screening & ${ }^{*} 44 \% \mathrm{M},{ }^{*} 44 \% \mathrm{~F}$ & ${ }^{*} 44 \% \mathrm{M},{ }^{*} 44 \% \mathrm{~F}$ & ${ }^{*} 34 \% \mathrm{M},{ }^{*} 34 \% \mathrm{~F}$ \\
\hline $1.220 \%$ increase in screening & ${ }^{*} 44 \% \mathrm{M},{ }^{*} 44 \% \mathrm{~F}$ & ${ }^{*} 44 \% \mathrm{M},{ }^{*} 44 \% \mathrm{~F}$ & ${ }^{*} 34 \% \mathrm{M},{ }^{*} 34 \% \mathrm{~F}$ \\
\hline 1.3 Increase in screening up to $100 \%$ & ${ }^{*} 44 \% \mathrm{M},{ }^{*} 44 \% \mathrm{~F}$ & ${ }^{*} 44 \% \mathrm{M},{ }^{*} 44 \% \mathrm{~F}$ & ${ }^{*} 34 \% \mathrm{M},{ }^{*} 34 \% \mathrm{~F}$ \\
\hline \multicolumn{4}{|l|}{ BI Scenarios } \\
\hline $2.110 \%$ increase in $\mathrm{BI}$ & ${ }^{*} 44 \% \mathrm{M},{ }^{*} 44 \% \mathrm{~F}$ & ${ }^{*} 44 \% \mathrm{M},{ }^{*} 44 \% \mathrm{~F}$ & ${ }^{*} 4 \% \mathrm{M},{ }^{*} 34 \% \mathrm{~F}$ \\
\hline $2.220 \%$ increase in $\mathrm{BI}$ & ${ }^{*} 44 \% \mathrm{M},{ }^{*} 44 \% \mathrm{~F}$ & ${ }^{*} 44 \% \mathrm{M},{ }^{*} 44 \% \mathrm{~F}$ & ${ }^{*} 34 \% \mathrm{M},{ }^{*} 34 \% \mathrm{~F}$ \\
\hline 2.3 Increase in BI up to $100 \%$ & ${ }^{*} 44 \% \mathrm{M},{ }^{*} 44 \% \mathrm{~F}$ & ${ }^{*} 44 \% \mathrm{M},{ }^{*} 44 \% \mathrm{~F}$ & ${ }^{*} 34 \% \mathrm{M},{ }^{*} 34 \% \mathrm{~F}$ \\
\hline \multicolumn{4}{|l|}{ Screening and BI Scenarios } \\
\hline $3.110 \%$ increase in screening $\& \mathrm{BI}$ & ${ }^{*} 44 \% \mathrm{M},{ }^{*} 44 \% \mathrm{~F}$ & ${ }^{*} 44 \% \mathrm{M},{ }^{*} 44 \% \mathrm{~F}$ & ${ }^{*} 34 \% \mathrm{M},{ }^{*} 34 \% \mathrm{~F}$ \\
\hline $3.220 \%$ increase in screening \& $\mathrm{BI}$ & ${ }^{*} 44 \% \mathrm{M},{ }^{*} 44 \% \mathrm{~F}$ & ${ }^{*} 44 \% \mathrm{M},{ }^{*} 44 \% \mathrm{~F}$ & ${ }^{*} 34 \% \mathrm{M},{ }^{*} 34 \% \mathrm{~F}$ \\
\hline 3.3 Increase in screening \& Bl up to $100 \%$ & ${ }^{*} 44 \% \mathrm{M},{ }^{*} 44 \% \mathrm{~F}$ & ${ }^{*} 44 \% \mathrm{M},{ }^{*} 44 \% \mathrm{~F}$ & ${ }^{*} 34 \% \mathrm{M},{ }^{*} 34 \% \mathrm{~F}$ \\
\hline
\end{tabular}

Table 2: Sensitivity changes in the effectiveness rates for pathway 1 and/or pathway 2 of the decision model.

${ }^{*}$ Percentage increments

${ }^{* *}$ A: Effectiveness for BI (Pathway 1) is increased by $10 \%$ from baseline without modifying effectiveness for screening (Pathway 2)

${ }^{* * *} \mathrm{~B}$ : Effectiveness for BI (Pathway 1 ) is decreased by $10 \%$ from baseline; and,

${ }^{* * * *} \mathrm{C}$ : Effectiveness for screening (Pathway 2) is decreased by $5 \%$ from baseline.

\section{Estimating costs}

Costs of training sessions: In line with its community wideapproach, pharmacists and other health professionals in the 10

\begin{tabular}{|c|c|c|c|c|c|c|c|c|c|}
\hline \multirow{2}{*}{$\begin{array}{l}\text { Costs } \\
\\
\begin{array}{l}\text { Costs for } \\
\text { pharmacists that } \\
\text { attended training } \\
(n=9)^{*}\end{array}\end{array}$} & \multirow{2}{*}{$\begin{array}{l}\begin{array}{l}\text { Training } \\
\text { materials }\end{array} \\
\$ 30 / \text { booklet }\end{array}$} & \multirow{2}{*}{$\begin{array}{l}\begin{array}{l}\text { Trainer } \\
\text { hours }\end{array} \\
\$ 200 / \text { hour }\end{array}$} & \multicolumn{2}{|c|}{ Trainer travel } & \multirow{2}{*}{$\begin{array}{l}\text { Trainer } \\
\text { accommodation } \\
+ \text { meals }\end{array}$} & \multirow{2}{*}{$\begin{array}{l}\begin{array}{l}\text { Venue hire/ } \\
\text { training } \\
\text { session }\end{array} \\
\text { \$100/ evening }\end{array}$} & \multirow{2}{*}{$\begin{array}{l}\text { Catering } \\
\text { \$40/ person }\end{array}$} & \multirow{2}{*}{$\begin{array}{l}\begin{array}{l}\text { Pharmacist } \\
\text { s' time }\end{array} \\
\begin{array}{l}\$ 38.70 / \\
\text { hour }\end{array}\end{array}$} & \multirow[t]{2}{*}{ Total cost } \\
\hline & & & $\begin{array}{l}\$ 290 / \\
\text { airline ticket }\end{array}$ & $\begin{array}{l}\$ 56 / \\
\text { hour }\end{array}$ & & & & & \\
\hline Unit /cost element & 1 & 8 & 1 & 10 & 1 & 1 & 1 & 2.5 & \\
\hline Quantity & 9 & 3 & 7 & 1 & 8 & 8 & 10 & 9 & \\
\hline Total Cost & $\$ 270$ & $\$ 4,800$ & $\$ 2,030$ & $\$ 560$ & $\$ 1,040$ & $\$ 800$ & $\$ 400$ & $\$ 871$ & $\$ 10,771$ \\
\hline $\begin{array}{l}\text { Average cost per } \\
\text { pharmacist }\end{array}$ & & & & & & & & & $\$ 1,197$ \\
\hline $\begin{array}{l}\text { Costs if } 13 \\
\text { pharmacists } \\
\text { attended training }\end{array}$ & & & & & & & & & \\
\hline
\end{tabular}

experimental communities in the AARC project were invited to participate in training sessions to provide them with improved skills for delivering opportunistically screening and BI for alcohol in a 5-10 minute period [20]. Training sessions were conducted by drug and alcohol clinical experts in late 2004 or 2005 and each lasted approximately $2 \frac{1}{2}$ hours: an hour focusing on BIs for risky drinking; a half-hour on practical BI techniques including the AUDIT screening tool; and an hour focused on case-studies. Costs in 2005/2006 Australian dollars (AUD), for training materials, trainer hours, travel costs, food and accommodation, venue per training session, catering, and the opportunity costs of pharmacists' time, were obtained as part of the AARC project and are included in the analysis (Table 3). 
Citation: Navarro HJ, Shakeshaft A, Doran CM, Petrie DJ (2014) The Potential Cost-Effectiveness of Pharmacist Delivered Brief Intervention for Alcohol Misuse. J Gen Practice 2: 173. doi:10.4172/2329-9126.1000173

Page 5 of 10

\begin{tabular}{|c|c|c|c|c|c|c|c|c|c|}
\hline Unit/cost element & 1 & 8 & 1 & 10 & 1 & 1 & 1 & 2.5 & \\
\hline Quantity & 13 & 3 & 7 & 1 & 8 & 8 & 14 & 13 & \\
\hline Total Cost & $\$ 390$ & $\$ 4,800$ & $\$ 2,030$ & $\$ 560$ & $\$ 1,040$ & $\$ 800$ & $\$ 560$ & $\$ 1,258$ & $\$ 11,438$ \\
\hline $\begin{array}{l}\text { Average cost per } \\
\text { pharmacist }\end{array}$ & & & & & & & & & $\$ 880$ \\
\hline $\begin{array}{l}\text { Costs if all } \\
\text { pharmacists } \\
\text { attended training } \\
(n=44)^{* * *}\end{array}$ & & & & & & & & & \\
\hline Unit /cost element & 1 & 8 & 1 & 10 & 1 & 1 & 1 & 2.5 & \\
\hline Quantity & 44 & 3 & 7 & 1 & 8 & 8 & 45 & 44 & \\
\hline Total Cost & $\$ 1,320$ & $\$ 4,800$ & $\$ 2,030$ & $\$ 560$ & $\$ 1,040$ & $\$ 800$ & $\$ 1,800$ & $\$ 4,257$ & $\$ 16,607$ \\
\hline $\begin{array}{l}\text { Average cost per } \\
\text { pharmacist }\end{array}$ & & & & & & & & & $\$ 377$ \\
\hline
\end{tabular}

Table 3: Summary of training costs for pharmacists in BI skills in experimental communities (2005-2006 AUD prices).

${ }^{*}$ Training costs for 9 pharmacists that attended training are used for scenarios 1.1, 2.1, and 3.1 (Table 2).

${ }^{* *}$ For scenarios $1.2,2.2$, and 3.2 an additional 4 pharmacists are proportionally added from a total of 44 pharmacists to training costs (Table 2).

${ }^{* * *}$ Training costs if all 44 pharmacists had attended training are used for scenarios 1.3, 2.3, and 3.3 (Table 2).

Cost of providing pharmacist's services: In general, delivering BI in community pharmacies is free-of-charge to the customer. Further, customer's travel and time expenses to visit a pharmacy are a sunk cost as they may have already been incurred by the customer for other pharmacy purposes. However, there is an opportunity cost of the pharmacist's time. The value of a pharmacist's time can be estimated using the average hourly salary of a pharmacist (i.e. AUD $\$ 38.70$, including additional employer superannuation contributions) in New South Wales (NSW), Australia [37]. Given opportunistic screening and delivery of $\mathrm{BI}$ to risky drinkers has a recommended average duration of 5-10 minutes [5,20,28], provision of screening (on average three minutes) would cost AUD\$1.94 per customer, and the provision of screening and BI (on average five minutes) would cost AUD $\$ 3.23^{1}$, on the assumption that more time is required for delivering a $\mathrm{BI}$ than for screening.

Incremental costs-effectiveness ratios: Incremental costeffectiveness ratios (ICERs) were estimated by dividing the difference in costs by the additional number of risky drinkers reducing alcohol consumption from screening, with or without BI, for each of the nine scenarios relative to current practice (Table 4 ). The additional costs for resources used (training, screening and delivering BI) were measured in AUD. Training costs were incorporated to the ICERs for the nine scenarios as follows. For scenarios 1.1, 2.1 and 3.1 (Table 1) the cost of training the nine pharmacists in BI (AUD\$10,771) who actually attended the training sessions was applied (Table 3), on the assumption that this is the minimal effort required to increase pharmacist screening or BI by $10 \%$. For scenarios 1.3, 2.3, 3.3 and for the sensitivity analysis (Table 1), the cost that would have been required to train all 44 pharmacists (AUD\$16,607) in the AARC experimental communities was applied (Table 3), on the assumption that all pharmacists would need to be trained in order for them to screen all their customers and provide a BI to all risky drinkers who visit them. For scenarios 1.2, 2.2, and 3.2 (Table 1), the cost that would have been required to train 13 pharmacists (AUD\$11,438) was calculated and applied, on the basis of proportionally distributing the cost of training the remaining 35 pharmacists (44 less the nine who attended) to each $10 \%$ increase in screening and BI (training an additional 3.89 pharmacists is assumed to be required for each $10 \%$ increase on screening or provision of $\mathrm{BI}$ ).

\section{Results}

\section{Number of presumptive risky drinkers}

Figure 2 shows that in 2006 a total of 17,030 presumptive risky drinkers (12,283 males; 4,747 females) aged 18-62 were identified in the 10 experimental communities.

\section{Data applied to AARC communities}

Figure 1 summarizes the different pathways risky drinkers can take when visiting a community pharmacy in a year. Based on current practice, approximately 16,470 presumptive risky drinkers visit a pharmacist annually (97\% of all risky drinkers in the community: 11,913 males; 4,557 females). Of these, 659 would be screened ( $4 \%$ of all risky drinkers in the community: 477 males; 182 females), 7 would receive $\mathrm{BI}(0.04 \%$ of all risky drinkers in the community: 5 males; 2 females), and 3 would reduce their drinking ( $0.02 \%$ of all risky drinkers in the community: 2 male; 1 female). In addition, 189 risky drinkers would be screened but not receive a BI and reduce their drinking ( $1 \%$ of all risky drinkers in the community: 137 males; 52 females), while 3,620 risky drinkers would not be screened, not receive a BI and still reduce their alcohol consumption $(21 \%$ of all risky drinkers in the community: 2,745 males; 875 females). Therefore, based on current practice, it is expected that a total of 3,812 risky drinkers who visit a pharmacist in a 12 month period would reduce their alcohol consumption $(3+189+3,620)$, representing $22 \%$ of all risky drinkers in the community $(3,812 / 17,030)$. 
Citation: Navarro HJ, Shakeshaft A, Doran CM, Petrie DJ (2014) The Potential Cost-Effectiveness of Pharmacist Delivered Brief Intervention for Alcohol Misuse. J Gen Practice 2: 173. doi:10.4172/2329-9126.1000173

Page 6 of 10

\section{Cost estimations of implementing BI}

Table 4 summarizes the outcome of current practice from the decision model and the nine scenarios. The total cost of current practice of pharmacist screening and BI delivery was estimated at AUD\$5,210. If the optimal scenario was achieved, where all presumptive risky drinkers visiting a pharmacist in a year were screened and receive a BI (scenario 3.3), approximately 5,600 would reduce their drinking (33\% of all risky drinkers in the community: $5,600 / 17,030)$ and the total cost would increase to AUD\$199,523, with an ICER of AUD\$36 per additional risky drinker reducing alcohol consumption relative to current practice. If all risky drinking customers (100\%) were to be screened alone (scenario 1.3), this would be the most cost-effective outcome, with an ICER of AUD $\$ 31$ per additional risky drinker reducing alcohol consumption relative to current practice. Conversely, the least cost-effective outcome would be a $10 \%$ increase in BI (scenario 2.1), with an ICER of AUD $\$ 3,334$ per additional risky drinker reducing alcohol consumption relative to current practice. An increase of $10 \%$ and $20 \%$ in both screening and delivery of BI (scenarios 3.1and 3.2) would result in $0.5 \%(86 / 17,030)$ and $1.7 \%(282 / 17,030)$ of all risky drinkers who visit a pharmacist reducing their drinking, with an ICER of AUD\$50 and AUD\$40 per additional risky drinker reducing consumption relative to current practice respectively.

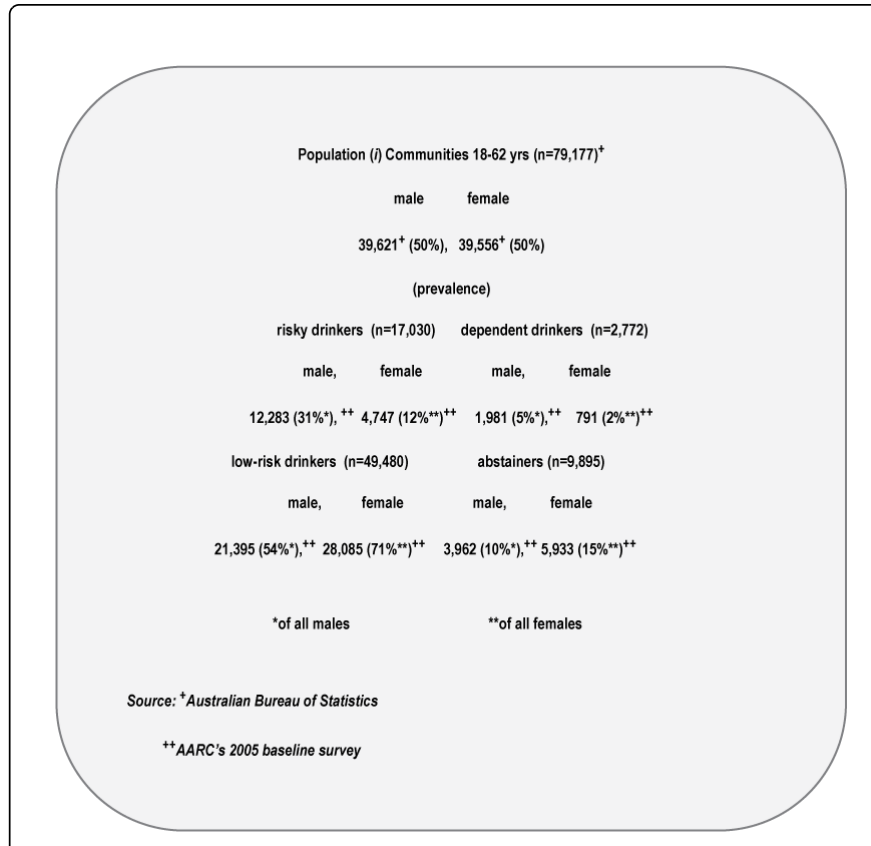

Figure 2: Decision model for presumptive risky drinkers receiving pharmacist-delivered screening and BI for alcohol misuse.

\begin{tabular}{|c|c|c|c|c|c|c|c|c|c|}
\hline $\begin{array}{l}\text { (n) Total risky } \\
\text { drinkers } \\
17,030^{*}\end{array}$ & $\begin{array}{l}\text { Low-risk } \\
\text { drinkers } \\
\text { screened (n) }\end{array}$ & $\begin{array}{l}\text { Dependent } \\
\text { drinkers } \\
\text { screened (n) }\end{array}$ & $\begin{array}{l}\text { Risky } \\
\text { drinkers } \\
\text { screened (n) }\end{array}$ & $\begin{array}{l}\text { Risky drinkers } \\
\text { screened but } \\
\text { not offered a } \\
\text { BI reducing } \\
\text { drinking (n) }\end{array}$ & 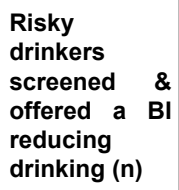 & $\begin{array}{l}\text { Total } \\
\text { cost }^{* *} \\
(2005-20 \\
06 \text { AUD) }\end{array}$ & $\begin{array}{l}\text { Addition } \\
\text { al cost }\end{array}$ & $\begin{array}{l}\text { Additional } \\
\text { number of } \\
\text { risky drinkers } \\
\text { reducing their } \\
\text { alcohol } \\
\text { consumption }\end{array}$ & $\begin{array}{l}\text { ICERs }^{* * *} \text { per } \\
\text { additional } \\
\text { risky drinker } \\
\text { reducing } \\
\text { alcohol } \\
\text { consumption }\end{array}$ \\
\hline Current practice & 1,909 & 107 & 659 & 189 & 2 & $\$ 5,210$ & - & - & - \\
\hline \multicolumn{10}{|l|}{ Nine scenarios } \\
\hline \multicolumn{10}{|l|}{$\begin{array}{l}\text { Screening } \\
\text { scenarios }\end{array}$} \\
\hline $\begin{array}{ll}1.1 & 10 \% \\
\text { increase s }\end{array}$ & 6,680 & 375 & 2,306 & 662 & 8 & $\$ 29,006$ & $\$ 23,796$ & 481 & $\$ 49$ \\
\hline $\begin{array}{ll}1.2 & 20 \% \\
\text { increase s }\end{array}$ & 11,451 & 643 & 3,953 & 1,135 & 13 & $\$ 42,698$ & $\$ 37,488$ & 957 & $\$ 39$ \\
\hline $1.3100 \% \mathrm{~s}$ & 47,714 & 2,681 & 16,470 & 4,729 & 56 & $\$ 146,857$ & $\begin{array}{l}\$ 141,64 \\
7\end{array}$ & 4,593 & $\$ 31$ \\
\hline \multicolumn{10}{|l|}{ BI Scenarios } \\
\hline $\begin{array}{ll}2.1 & 10 \% \\
\text { increase i }\end{array}$ & 1,909 & 107 & 659 & 170 & 25 & $\$ 16,194$ & $\$ 10,984$ & 3 & $\$ 3,334$ \\
\hline $\begin{array}{ll}2.2 & 20 \% \\
\text { increase i }\end{array}$ & 1,909 & 107 & 659 & 151 & 47 & $\$ 17,074$ & $\$ 11,864$ & 7 & $\$ 1,801$ \\
\hline $2.3100 \% \mathrm{i}$ & 1,909 & 107 & 659 & 0 & 224 & $\$ 23,924$ & $\$ 18,714$ & 33 & $\$ 574$ \\
\hline \multicolumn{10}{|l|}{$\begin{array}{l}\text { Screening and } \mathrm{BI} \\
\text { scenarios }\end{array}$} \\
\hline $\begin{array}{l}3.1 \quad 10 \% \\
\text { increase } s+i\end{array}$ & 6,680 & 375 & 2,306 & 595 & 86 & $\$ 29,751$ & $\$ 24,541$ & 490 & $\$ 50$ \\
\hline
\end{tabular}


Citation: Navarro HJ, Shakeshaft A, Doran CM, Petrie DJ (2014) The Potential Cost-Effectiveness of Pharmacist Delivered Brief Intervention for Alcohol Misuse. J Gen Practice 2: 173. doi:10.4172/2329-9126.1000173

Page 7 of 10

\begin{tabular}{|l|l|l|l|l|l|l|l|l|l|}
\hline $\begin{array}{c}3.2 \\
\text { increase } \mathrm{s}+\mathrm{i}\end{array}$ & 11,451 & 643 & 3,953 & 906 & 282 & $\$ 45,252$ & $\$ 40,042$ & 996 & $\$ 40$ \\
\hline $3.3100 \% \mathrm{~s}+\mathrm{i}$ & 47,714 & 2,681 & 16,470 & 0 & 5,600 & $\$ 199,523$ & $\begin{array}{l}\$ 194,31 \\
3\end{array}$ & 5,408 & $\$ 36$ \\
\hline
\end{tabular}

Table 4: Customers' costs per presumptive risky drinker reducing alcohol consumption.

${ }^{*}$ Total (n) risky drinkers in the intervention communities (Figure 1); risky drinkers estimated to have visited a pharmacist in $2006=$ 16,470 (Figure 2).

${ }^{* *}$ Total cost includes the cost of screening and/or delivering BI, and training costs (Table 1): scenarios 1.1, 2.1 and 3.1 (AUD\$10,771); scenarios 1.2, 2.2 and 3.2 (AUD \$11,438); scenarios 1.3, 2.3, 3.3 (AUD $\$ 16,607)$.

${ }^{* * *}$ ICERS are calculated per additional risky drinker reducing alcohol consumption from screening with and without Brief Intervention relative to current practice.

$\mathrm{s}=$ screening; $\quad \mathrm{i}=$ intervention; $\mathrm{BI}=$ brief intervention; $\mathrm{AUD}=$ Australian dollars; ICERs $=$ incremental cost-effectiveness ratios.

\section{Sensitivity analyses}

By increasing only the effectiveness of pharmacists screening and BI to $44 \%$ (pathway one), screening and providing a BI to all risky drinking customers (scenario 3.3) in the community who visit them each year, would result in an estimated $43 \%(7,247 / 17,030)$ of all risky drinkers reducing their alcohol consumption, with an ICER of AUD $\$ 28$ per additional risky drinker reducing alcohol consumption relative to current practice. Due to this $10 \%$ increase in effectiveness for pathway one, scenario 3.3 would be the most cost-effective option rather than screening all their risky drinking customers (scenario 1.3). Although the least cost-effective option would still be a $10 \%$ increase in the provision of BI (scenario 2.1) compared to current practice, the $10 \%$ increment in effectiveness for pathway one would reduce the ICER by more than half (67\%) from AUD\$3,334 to AUD $\$ 1,111$ per additional risky drinker reducing alcohol consumption.

Increasing the effectiveness for pathway one by $10 \%$ and for pathway two by $5 \%$, again screening all their risky drinking customers (scenario 1.3) would be the most cost-effective option per additional risky drinker reducing alcohol consumption, but with a slightly lower ICER of AUD\$26 2. In addition, the least cost-effective option would remain the $10 \%$ increase in the provision of $\mathrm{BI}$ (scenario 2.1), with an ICER of AUD $\$ 1,667$ per additional risky drinker reducing alcohol consumption relative to current practice.

\section{Discussion}

The estimates in the decision model show that, based on current practice, approximately $22 \%$ of all presumptive risky drinkers visiting pharmacists in these rural communities would reduce alcohol consumption in a year, of which $0.02 \%$ would do so because of pharmacist screening and BI and $1 \%$ would do so because of pharmacist screening only. In addition, the potential number of risky drinkers who would reduce alcohol consumption if all risky drinkers visiting a pharmacist each year were screened and offered a BI has also been identified. At best, if all pharmacists in a defined community provided screening and BI, approximately $33 \%$ of presumptive risky drinkers would reduce their alcohol consumption by an average of $22.4 \mathrm{~g} / \mathrm{wk}$. The most cost-effective option per additional risky drinker who reduces consumption, relative to current practice, is to ensure all risky drinkers who visit a pharmacist are screened, without having to increase the rate of BI provision (ICER of AUD\$29). Before discussing these findings in detail, a number of potential methodological limitations of the analyses should be noted.

The prevalence of alcohol misuse in this analysis was based on selfreported alcohol consumption and extrapolated to the population, which may not accurately represent true levels of problem drinking in the community for three reasons. Firstly, respondents may underreport their drinking. Secondly, those who completed the survey may not be representative of the communities: since females and older people are over-represented in the sample [38], it is possible that true rates of risky drinking in the communities are higher. Although this possibility would increase the numbers of risky drinkers for the different strategies, it makes no difference to the cost-effectiveness per additional risky drinkers who reduce their alcohol consumption in each scenario, relative to current practice. Thirdly, the reliability and validity of the AUDIT questionnaire for population, as opposed to clinical, samples has been questioned [39]. However, AUDIT has been used in population surveys [40-42] where its test/retest reliability has been found to be high [42] and its concurrent validity adequate in relation to four criteria: high-volume drinking, alcohol-related social problems, alcohol-related health problems, and alcohol dependence $[43,44]$.

The input parameters for this model, extrapolated from the data sources for current practice rates of screening and delivery of BI, may have a degree of uncertainty because the questions in the community survey used to estimate the proportion of risky drinkers who go to a pharmacy and receive a BI have no demonstrated reliability and validity for this purpose. This potential limitation was addressed by using a modelling technique with a range of scenarios and different increments in the rates of screening and BI, including a 'best estimate' (scenario 3.3), to predict different potential numbers of risky drinkers being screened and receiving a BI [45].

The estimate of the mean proportion of drinkers who reduce alcohol consumption from pharmacist delivered BI, extracted from the two only published studies identified [20,29], refers to any reduction in consumption, rather than a reduction in risk levels specified in national drinking guidelines [46,47], which may limit the clinical significance of reductions in alcohol-related harm associated with reduced consumption. Similarly, since these two studies did not report reductions in alcohol consumption in control groups (screening only), the percentage of risky drinkers who reduce their drinking from screening only was estimated on the uncertain assumptions that screening alone is less effective than screening and BI and more effective than no screening and no BI.

Despite the potential limitations of this analysis, this model has identified the potential number of risky drinkers who would reduce alcohol consumption if all risky drinkers visiting a pharmacist were 
screened and offered a BI. At best, if all pharmacists in a defined community provided screening and BI, approximately $34 \%$ of presumptive risky drinkers would reduce their alcohol consumption by an average of $22.4 \mathrm{~g} / \mathrm{wk}$. In reality, these "optimal" outcomes are impractical. Previous attempts to identify and intervene with risky drinkers in pharmacy settings have resulted in very low customer recruitment rates [20,29,48]. A recent study, for example, only achieved $43 \%(237 / 102)$ participation rate for the completion of a survey, in which respondents raised concerns about a lack of privacy, even if BI was to be conducted in a private consultation room [17]. In addition, available research about current practice of alcohol BI in pharmacy settings in a community shows that approximately $5 \%$ of risky drinking customers are screened for alcohol misuse, and even fewer are provided feedback on the potential impact of their alcohol consumption on their health [49].

Furthermore, implementation of BIs for alcohol misuse in community pharmacies need to be underpinned by appropriate and, arguably more thorough training programs than for GPs to improve their alcohol knowledge and confidence in screening and delivering a BI $[49,50]$. However, based on attendance at the pharmacists' training sessions organized for the AARC project (21\%), the majority of pharmacists appear unwilling to engage in training to provide screening and BI for alcohol misuse, despite the training sessions being free and locally advertised. Nevertheless, previous research does show pharmacists are regarded as a valuable source of information on health education and referral $[17,20,23-26]$ and that the provision of relevant information on alcohol and other drug interactions is an accepted part of their medication dispensing role $[17,20,27]$. Whether this acceptability on the part of the community extends to receiving unsolicited alcohol advice is unclear, although recent evidence highlights the importance of customers' privacy and the need to involve pharmacists and their staff in designing the delivery of alcohol screening and BI [51].

Generalisability of results is acknowledged as a major concern in the BI alcohol literature given considerable variation in published estimates and their implications for routine practice [4,11], as well as estimating different costs in different settings [52]. Consequently, this study employed nine different scenarios, including a 'best case' (scenario 3.3), to test the robustness of the results. In relation to the ICER estimates, extrapolation of unit costs of pharmacists' time can be reasonably adapted to local payment systems [20] since the time required for opportunistic engagement to deliver $\mathrm{BI}$ is structured and consistent across primary care [5,52] and has been suggested for pharmacy settings [20]. In addition, in this analysis training costs in BI reflect costs of training pharmacists in 10 communities. Although local adjustments would have to be made to specific training program costs elsewhere, proportionally distributing these cost adjustments across the ICERs of the nine scenarios would still result in scenario 1.3 being the most cost-effective relative to current practice.

Given the preferred model in the literature appears to be providing BI after screening in a private area in the pharmacy, this model would increase the opportunity cost to pharmacists because it implies a need to establish such a private area if it is not already available in the pharmacy and additional time to transfer relevant customers to this area $[17,20,26]$.

Arguably of greater concern is that this study shows that the more realistic outcomes, rather than optimal outcomes, do not appear to substantially reduce the proportion of risky drinkers in a community who would modify their alcohol consumption: a $10 \%$ and $20 \%$ increase in pharmacist screening and BI would achieve an estimated reduction in alcohol consumption for $0.5 \%$ and $1.7 \%$ of presumptive risky drinkers in a community [53,54]. Nevertheless, since the majority of scenarios in the decision model predict a greater proportion of potential risky drinkers would reduce their alcohol consumption as a result of screening alone, rather than screening and $\mathrm{BI}$, there is a clear need to determine the potential efficacy, effectiveness and efficiency of screening for alcohol misuse in community pharmacy settings [26].

Even though most RCT evaluations of BI for alcohol misuse delivered in general practice settings report a positive effect in reducing alcohol consumption, more research is needed to establish the potential health and social gains (the cost-benefit) of the reported mean difference of $38 \mathrm{~g} / \mathrm{wk}$ in alcohol consumption among intervention groups compared to controls $[5,6]$. Other uncertainties include the benefit of the duration and sustainability of BI effects, the effectiveness of screening alone [55], and the relative impact of primary care on drinking over time, compared to other factors: as shown by the decision model developed for this study, an estimated $22 \%$ of risky drinkers in a community will reduce their drinking without screening and BI by pharmacists, which may be attributable to younger drinkers reducing their consumption with age [56], or the effect of other intervention strategies, such as volumetric taxation of alcoholic beverages [9] and policing practices [57].

\section{Conclusion}

Previous research indicates that pharmacist-delivered screening and BI does appear to be feasible [28,29]. It is an important observation because pharmacists are able to access vulnerable sub-populations who rarely discuss their drinking behaviour with GPs, particularly young males [17]. This study shows that increasing the rates of screening to pharmacy customers who visit a pharmacy each year, with or without $\mathrm{BI}$ to risky drinkers detected, can be cost-effective per additional risky drinker reducing consumption, relative to current practice. Indeed, screening all customers in a pharmacy would achieve an estimated ICER of AUD\$31 per additional risky drinker reducing alcohol consumption relative to current practice. Pharmacy-delivered screening and $\mathrm{BI}$ is, however, unlikely to be an effective strategy for reducing the proportion of risky drinkers across a whole, defined population: a $10 \%$ and $20 \%$ increase in pharmacist screening and delivery of BI would only achieve an estimated reduction in alcohol consumption for $0.5 \%$ and $1.7 \%$ of presumptive risky drinkers in a community; in most cases customers and pharmacists appear reluctant to engage with screening and BI for alcohol misuse [49,54]; and almost all risky drinking pharmacy customers would need to be screened. From a community or population perspective, therefore, achieving substantial reductions in the prevalence of risky drinking will require strategies other than opportunistic screening and BI in pharmacies and indeed other primary care settings, such as GPs [14]: volumetric taxation of alcohol has been shown to be most cost-effective in achieving population level reductions among risky drinkers, followed by advertising bans on alcohol [9].

\section{Acknowledgement}

The full list of contributors to this project are listed elsewhere [30], but particular thanks to the 10 experimental communities, especially the Mayor of each community, and the local police, media and liquor accords who actively supported and promoted the study. 


\section{Ethics and Funding}

The research was approved by the Human Research Ethics Committee of the University of Newcastle, Australia (the Administering Institution), and was funded by the Foundation for Alcohol Research and Education (http://www.fare.org.au/about-us/). The Australian Government provides core funding to the National Drug and Alcohol Research Centre through the Substance Misuse Prevention and Service Improvement Grants Fund.

\section{References}

1. Australian Institute of Health and Welfare, 2010 National Drug Strategy Household Survey report, 2011, Australian Institute of Health and Welfare: Canberra.

2. National Health and Medical Research Council, Australian Guidelines to reduce health risks from drinking alcohol. 2009, Commonwealth of Australia: Canberra.

3. Beich A, Gannik D, Saelan H, Thorsen T (2007) Screening and brief intervention targeting risky drinkers in Danish general practice--a pragmatic controlled trial. Alcohol Alcohol 42: 593-603.

4. Kaner E, Bland M, Cassidy P, Coulton S, Deluca P, et al. (2009) Screening and brief interventions for hazardous and harmful alcohol use in primary care: A cluster randomised controlled trial protocol. BMC Public Health 9: 287.

5. Kaner EF, Beyer F, Dickinson HO, Pienaar E, Campbell F, et al. (2007) Effectiveness of brief alcohol interventions in primary care populations. Cochrane Database Syst Rev : CD004148.

6. Bertholet N, Daeppen JB, Wietlisbach V, Fleming M, Burnand B (2005) Reduction of alcohol consumption by brief alcohol intervention in primary care: systematic review and meta-analysis. Arch Intern Med 165: 986-995.

7. Kraemer KL (2007) The cost-effectiveness and cost-benefit of screening and brief intervention for unhealthy alcohol use in medical settings. Subst Abus 28: 67-77.

8. Kunz FM, French MT, Bazargan-Hejazi S (2004) Cost-effectiveness analysis of a brief intervention delivered to problem drinkers presenting at an inner-city hospital emergency department. J Stud Alcohol 65 363-370.

9. Cobiac L, Vos T, Doran C, Wallace A (2009) Cost-effectiveness of interventions to prevent alcohol-related disease and injury in Australia. Addiction 104: 1646-1655.

10. Chisholm D, Rehm J, Van Ommeren M, Monteiro M (2004) Reducing the global burden of hazardous alcohol use: a comparative costeffectiveness analysis. J Stud Alcohol 65: 782-793.

11. Nilsen P, Kaner E, Babor TF (2008) Brief intervention, three decades on. An overview of research findings and strategies for more widespread implementation. Nord Stud Alcohol Drugs 25: 453-467.

12. Nilsen P, Aalto M, Bendtsen P, Seppä K (2006) Effectiveness of strategies to implement brief alcohol intervention in primary healthcare. A systematic review. Scand J Prim Health Care 24: 5-15.

13. Funk M, Wutzke S, Kaner E, Anderson P, Pas L, et al. (2005) A multicountry controlled trial of strategies to promote dissemination and implementation of brief alcohol intervention in primary health care: Findings of a world health organization collaborative study. J Stud Alcohol 66: 379-388.

14. Navarro HJ, Shakeshaft A, Doran CM, Petrie DJ (2011) The potential cost-effectiveness of general practitioner delivered brief intervention for alcohol misuse: evidence from rural Australia. Addict Behav 36: 1191-1198.

15. Hetlevik $\varnothing$, Haug K, Gjesdal S (2010) Young people and their GP: a register-based study of 1717 Norwegian GPs. Fam Pract 27: 3-8.

16. Gleeson CR, Robinson MB, Neal RD (2002) A review of teenagers perceived needs and access to primary health care: Implications for health services. Primary Health Care Res Dev 3: 184-193.
17. Dhital R, Whittlesea CM, Norman IJ, Milligan P (2010) Community pharmacy service users' views and perceptions of alcohol screening and brief intervention. Drug Alcohol Rev 29: 596-602.

18. Livingston M, Room R (2009) Variations by age and sex in alcoholrelated problematic behaviour per drinking volume and heavier drinking occasion. Drug Alcohol Depend 101: 169-175.

19. Wilsnack RW, Vogeltanz ND, Wilsnack SC, Harris TR, Ahlström S, et al. (2000) Gender differences in alcohol consumption and adverse drinking consequences: cross-cultural patterns. Addiction 95: 251-265.

20. Dhital R (2008) Alcohol screening and brief intervention by community pharmacists: Benefits and communication methods. J Commun in Healthcare 1: 20-31.

21. Littlejohn C, Holloway A (2008) Nursing interventions for preventing alcohol-related harm. Br J Nurs 17: 53-59.

22. McPherson A (2005) Adolescents in primary care. BMJ 330: 465-467.

23. Sheridan J, Wheeler A, Ju-Hsing Chen L, Chen-Yun Huang A, Nga-Yee Leung I, et al. (2008) Screening and brief interventions for alcohol: attitudes, knowledge and experience of community pharmacists in Auckland, New Zealand. Drug Alcohol Rev 27: 380-387.

24. Anderson C, Blenkinsopp A, Armstrong M (2004) Feedback from community pharmacy users on the contribution of community pharmacy to improving the public's health: A systematic review of the peer reviewed and non-peer reviewed literature 1990-2002. Health Expect 7: 191-202.

25. Department of Health and Ageing.

26. Sheridan J, Smart R, McCormick R (2010) Estimating problem drinking among community pharmacy customers: what did pharmacists think of the method? See comment in PubMed Commons below Int J Pharm Pract 18: 290-296.

27. O'Donnell J (2005) Drug injury: Liability, analysis, and prevention. Lawyers \& Judges Publishing Company Inc.: Tucson, Arizona Second edn.

28. Watson MC, Blenkinsopp A (2009) The feasibility of providing community pharmacy-based services for alcohol misuse: a literature review. See comment in PubMed Commons below Int J Pharm Pract 17: 199-205.

29. Fitzgerald N, McCaig DJ, Watson H, Thomson D, Stewart DC (2008) Development, implementation and evaluation of a pilot project to deliver interventions on alcohol issues in community pharmacies. Int J Pharm Pract 16: 17-22.

30. Shakeshaft A, Doran C, Petrie D, Breen C, Havard A, et al. (2014) The Alcohol Action in Rural Communities (AARC) Project. The effectiveness of community-action in reducing risky alcohol consumption and harm: a cluster randomised controlled trial. PLOS Medicine 11:3.

31. Breen CL, Shakeshaft AP, Doran CM, Sanson-Fisher RW, Mattick RP (2010) Cost-effectiveness of follow-up contact for a postal survey: a randomised controlled trial. See comment in PubMed Commons below Aust N Z J Public Health 34: 508-512.

32. Australian Bureau of Statistics Census data online.

33. Shakeshaft AP, Bowman JA, Sanson-Fisher RW (2002) Communitybased drug and alcohol counselling: who attends and why? See comment in PubMed Commons below Drug Alcohol Rev 21: 153-162.

34. Babor TF, Higgins-Biddle JC, Saunders JB, Monteiro MG (2001) Audit: The alcohol use disorder identification test: Guidelines for use in primary health care.

35. Department of Veterans' Affairs Alcohol screen (audit).

36. Doran CM, Shakeshaft AP, Fawcett JE (2004) General practitioners' role in preventive medicine: scenario analysis using alcohol as a case study. See comment in PubMed Commons below Drug Alcohol Rev 23: 399-404.

37. (2006) The Association of Professional Engineers, S.M., Australia 2006 community \& hospital parmacists' remuneration survey report. The Association of Professional Engineers, Scientists \& Managers, Australia, Pharmacist Division: Melbourne.

38. Petrie D, Doran C, Shakeshaft A, Sanson-Fisher R (2008) The relationship between alcohol consumption and self-reported health status 
Citation: Navarro HJ, Shakeshaft A, Doran CM, Petrie DJ (2014) The Potential Cost-Effectiveness of Pharmacist Delivered Brief Intervention for Alcohol Misuse. J Gen Practice 2: 173. doi:10.4172/2329-9126.1000173

Page 10 of 10

using the EQ5D: evidence from rural Australia. Soc Sci Med 67: 1717-1726.

39. Berner MM, Kriston L, Bentele M, Härter M (2007) The alcohol use disorders identification test for detecting at-risk drinking: a systematic review and meta-analysis. J Stud Alcohol Drugs 68: 461-473.

40. Reinert DF, Allen JP (2002) The Alcohol Use Disorders Identification Test (AUDIT): a review of recent research. Alcohol Clin Exp Res 26: 272-279.

41. Fleming J (1996) The epidemiology of alcohol use in Australian women: findings from a national survey of women's drinking. Addiction 91: 1325-1334.

42. Selin KH (2003) Test-retest reliability of the alcohol use disorder identification test in a general population sample. Alcohol Clin Exp Res 27: $1428-1435$.

43. Selin KH (2006) Alcohol Use Disorder Identification Test (AUDIT): what does it screen? Performance of the AUDIT against four different criteria in a Swedish population sample. Subst Use Misuse 41: 1881-1899.

44. Shakeshaft AP, Bowman JA, Sanson-Fisher RW (1998) Comparison of Three Methods to Assess Binge Consumption: One-Week Retrospective Drinking Diary, AUDIT, and Quantity/Frequency. Subst Abus 19: 191-203.

45. Drummond MF, Sculpher MJ, Torrance GW, O'Brien BJ, Stoddart GL (2005) Methods for the economic evaluation of health care programmes. Third ed. Oxford University Press New York.

46. National Health and Medical Research Council Australian guidelines to reduce health risks from drinking alcohol.

47. United States Department of Agriculture and United States Department of Health and Human Services Dietary guidelines for americans. Chapter 9 - alcoholic beverages. P 43-46.

48. Goodall $\mathrm{T}$, Dawson $\mathrm{P}$ The role of comunity pharmacists in the identification and treatment of hazardous drinking.
49. McCaig D1, Fitzgerald N, Stewart D (2011) Provision of advice on alcohol use in community pharmacy: a cross-sectional survey of pharmacists' practice, knowledge, views and confidence. Int J Pharm Pract 19: 171-178.

50. Dhital R, Whittlesea CM, Milligan P, Khan NS, Norman IJ (2013) The impact of training and delivering alcohol brief intervention on the knowledge and attitudes of community pharmacists: a before and after study. Drug Alcohol Rev 32: 147-156.

51. Wutzke SE, Shiell A, Gomel MK, Conigrave KM (2001) Cost effectiveness of brief interventions for reducing alcohol consumption. Soc Sci Med 52: 863-870.

52. Peterson G, Tenni P, Jackson S, Bereznicki L, Hughes J, et al. (2009) Documenting clinical interventions in community pharmacy: Promise iii. Department of Health and Ageing: Canberra.

53. Horsfield E, Sheridan J, Anderson C (2011) What do community pharmacists think about undertaking screening and brief interventions with problem drinkers? Results of a qualitative study in new zealand and england. Int J Pharm Pract 19: 192-200.

54. Jenkins RJ1, McAlaney J, McCambridge J (2009) Change over time in alcohol consumption in control groups in brief intervention studies: systematic review and meta-regression study. Drug Alcohol Depend 100: 107-114.

55. Beich A, Gannik D, Malterud K (2002) Screening and brief intervention for excessive alcohol use: qualitative interview study of the experiences of general practitioners. BMJ 325: 870.

56. Doherty SJ, Roche AM (2003) Alcohol and licensed premises: Best practice in policing - a monograph for police and policy makers. Australasian Centre for Policing Research: Payneham SA.

57. Krska J, Mackridge AJ (2014) Involving the public and other stakeholders in development and evaluation of a community pharmacy alcohol screening and brief advice service. Public Health 128: 309-316.
This article was originally published in a special issue, entitled: "Effective Health Service Delivery to the Target Population", Edited by Jongwha Chang 